\title{
ELITES EMPRESARIAIS E A CONFIGURAÇÃO DE ESPAÇOS TURÍSTICOS NA ILHA DE COZUMEL, MÉXICO*
}

\author{
Lea Carvalho Rodrigues ${ }^{1}$
}

\begin{abstract}
Resumo: $\mathrm{O}$ artigo trata das relações entre turismo, elites empresariais e território no cenário atual de expansão mundial do turismo, uma das atividades mais importantes da economia mundial contemporânea, indicado por organismos internacionais como solução econômica aos países pobres e em desenvolvimento. Os dados etnográficos colhidos na ilha de Cozumel, México, no ano de 2011, permitem compreender a dimensão político-econômica na configuração dos seus espaços turísticos. A ilha é dominada por grupos empresariais locais com expressividade política, e nesta trama atuam o Estado, as agências internacionais e os interesses privados.
\end{abstract}

Palavras chave: turismo, território, elites empresariais, Cozumel, México.

Abstract: The article deals with the relationships between tourism, business elites and territory in the current scenario of the global expansion of tourism, one of the most important activities of the contemporary world economy, as indicated by international economic solution to poor and developing countries. The ethnographic data collected on the island of Cozumel, Mexico, in 2011, allow us to understand the politicaleconomic dimension in shaping their tourism spaces. The island is dominated by local business groups with political expression, and this plot act the state, international agencies and private interests.

Keywords: tourism, territory, local business groups, Cozumel, México.

* Os dados apresentados neste artigo resultam de atividades de pesquisa realizadas em Estágio Pós-doutoral no CIESAS/México, que contou com bolsa de pesquisa CAPES

${ }^{1}$ Professora Associada II da Universidade Federal do Ceará (UFC), na área de Antropologia do departamento de Ciências Sociais. 
|90|

Elites empresariais e a configuração de espaços...

\section{Introdução}

O presente artigo aborda as relações entre turismo e território, e o papel das elites político econômicas na configuração dos espaços turísticos, num cenário de grande expansão desta atividade a nível mundial. De fato, o turismo se tornou, nas últimas décadas do século passado, uma das atividades mais importantes da economia mundial, especialmente atrativa a investimentos em razão do rápido crescimento e diversificação das suas atividades. $\mathrm{O}$ volume de negócios é igual ou superior ao das exportações de alimentos ou de automóveis ${ }^{2}$, de forma que se tornou uma verdadeira indústria e, como tal, é considerada uma importante fonte de ingressos de divisas para os países em desenvolvimento (UNWTO, 2010)ํ․ Como destaca Marín (2010), esta indústria se erigiu como um sistema que se expande por diversas partes do mundo, manifestando-se como uma força potente global que define pautas de desenvolvimento econômico e formas de reprodução sociocultural em um grande número de regiões e localidades do planeta. Além do mais, o turismo produz profundas transformações socioespaciais e culturais, que geram novas formas de territorialidade.

O México, em particular, é um país que optou pelo turismo como um mecanismo econômico privilegiado para incremento de divisas, geração de empregos e desenvolvimento econômico. Há uma forte participação do Estado mexicano no planejamento do turismo, sobretudo a partir da criação do Fondo Nacional de Promoción del Turismo - FONATUR, nos anos 1970, que conseguiu vultosos recursos para fomentar os investimentos no setor turístico. Tendo Cancún se tornado um dos balneários mais famosos do mundo, o estado de Quintana-Roo, onde ele se situa, adquiriu centralidade nessas políticas.

\footnotetext{
2 Segundo dados da Organização Mundial do Turismo, em 2001 o total de recursos gerados para os países visitados, que foi de US\$ 477 milhões, passou a US\$ 852 milhões em 2009.

${ }^{3}$ http://www.unwto.org/aboutwto/his/en/his.php?op=5, consulta em 28/06/2010.
} 
Diversas pesquisas científicas sobre esta região apontam consequências tanto positivas como negativas da expansão desenfreada do turismo: impactos físico-ambientais (reconfigurações espaciais e alterações do ecossistema), demográficos (resultado dos processos migratórios para os polos turísticos), socioculturais e econômico-financeiros ${ }^{4}$. Tais processos estimularam a formulação de uma proposta de pesquisa, que foi por mim realizada durante o ano de 2011, no México, com o intuito de compreender as configurações socioespaciais e culturais geradas pelo processo de turistificação em uma região de praia ${ }^{5}$, bem como os efeitos sobre as populações locais. Para atingir este objetivo, procurei compreender: i) a inserção dos distintos agentes locais nesse processo e o grau de participação, autonomia e poder das partes envolvidas; ii) a dinâmica das relações estabelecidas entre as instâncias públicas, empresários, turistas e moradores, no que se refere às disputas e/ou negociações do espaço turístico, e como ocorria o processo de criação de novas espacialidades; e, por fim, iii) os efeitos sobre a população local quanto à posse da terra, aos benefícios econômicos das atividades turísticas e às dimensões social e cultural.

O recorte empírico para a realização da pesquisa no México foi a Ilha de Cozumel, localizada na península de Yucatán, no estado de Quintana-Roo, em pleno Mar do Caribe e a 18 quilômetros do continente, onde está o corredor turístico denominado Riviera Maya, que vai de Cancún (ao Norte) a Tulum (ao Sul).

4 A respeito veja, entre outros: Marín (2008, 2010); López y Marín (2011), Ribeiro e Barros (19), Bringas (1999), Arroyo y Gutiérrez (2007); González y Palafox (2006), Palafox y Zizumbo (2009). ${ }^{4}$ A escolha de um destino turístico de praia se deveu aos objetivos de comparação com os resultados de pesquisas que então eu vinha realizando no Brasil, na costa Cearense, no âmbito do projeto Antropologia e políticas públicas: incentivo ao turismo no extremo-oeste da costa cearense e efeitos sobre populações locais. Tal projeto contou com o aporte de recursos do CNPq via bolsas de pesquisa. 
|92|

Elites empresariais e a configuração de espaços...

A princípio esta escolha se deveu a alguns dados instigantes encontrados em trabalhos acadêmicos, que informavam tratar-se de uma ilha dotada tanto de belezas naturais, que a tornaram um destino turístico de bastante importância - seus arrecifes de coral pertencentes ao Sistema Arrecifal Mesoamericano, o mais extenso do hemisfério, com cerca de $900 \mathrm{Km}$ de extensão, costeando México, Guatemala, Belize e Honduras ${ }^{6}$ - e a existência de uma rica herança arqueológica, por ter sido habitada pelos mayas até o ano 300 de nossa era (Sánchez y Propin, 2003). No passado préhispânico foi um porto comercial de importância, bem como um centro cerimonial onde era cultuada a deusa Ixchel, da fertilidade, razão porque seria um importante local de peregrinação para as populações mayas habitantes do continente.

\section{Figura I - localização da Ilha de Cozumel em relação ao território mexicano}

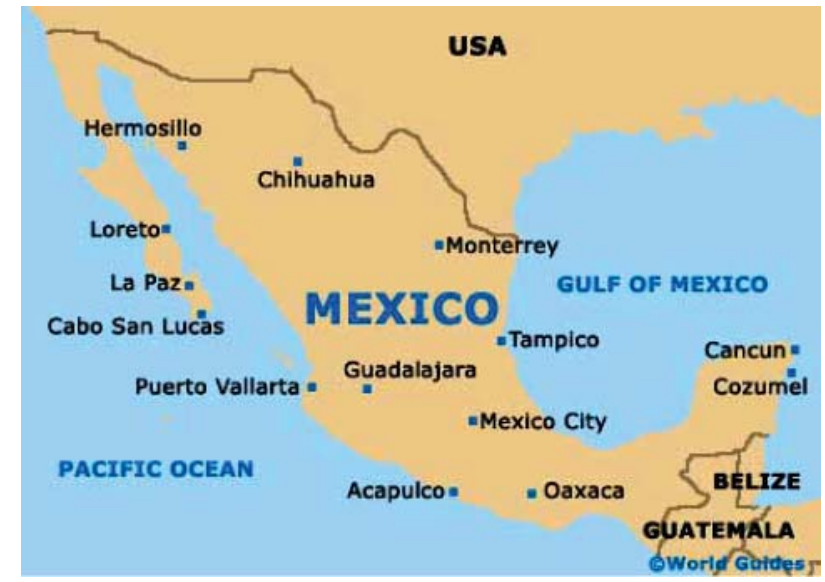

Fonte: cozumel.world-guides.com.

\footnotetext{
${ }^{6}$ Para maiores informações vide SEMANARP (1998).
} 
Outra razão para esta escolha, não mais empírica, dizia respeito às possibilidades de discussão teórica no campo da antropologia contemporânea, uma vez que Cozumel apresenta características particulares quanto ao turismo internacional: é uma ilha, mas tem um aeroporto internacional, portos e estradas, além de uma boa zona hoteleira. Ademais, como a atividade turística concentra-se no ramo de cruzeiros e recebe um número elevado de turistas que sequer chegam a conhecer o continente mexicano, podendo, portanto, ser considerada um enclave turístico por excelência que permite discutir teoricamente conceitos como transnacionalidade (Ribeiro, 1997; Schiller, 2007) fluxos, territorialização e desterritorialização (Hannerz, 2001).

Com estas informações e estes anseios quanto à pesquisa foi que aterrizei no México, em janeiro de 2001. O período de três meses passados na sede do Centro de Investigaciones y Estudios Superiores en Antropología Social - CIESAS, Unidade Peninsular, na cidade de Mérida, estado de Yucatán, antes da ida para Cozumel onde eu realizaria as atividades do trabalho de campo, colocaramme frente a novos dados e questões. Por um lado, inteirei-me da existência de uma elite econômica na ilha que detém também o poder político em todo o estado de Quintana-Roo. Por outro, acessando dados do Registro Agrario Nacional (RAN), eu soube que a totalidade da ilha havia sido constituída como ejido no ano de 15. Ou seja, suas terras $(42,120$ hectares, menos o fundo legal do município de 3,717 hectares) haviam sido objeto da Lei Agrária que distribuiu as terras agricultáveis entre os camponeses por meio do sistema de formação de ejidos, terras de uso coletivo.

As terras ejidales de Cozumel, no entanto, foram expropriadas em 31,658 hectares no ano de 1974, quando o governo mexicano iniciou o forte investimento em turismo com a inauguração de Cancún. Ademais, a bibliografia existente sobre a ilha de Cozumel, sobretudo a referida a historiadores (Ramos, 1999; César y Arnaiz,

${ }^{7}$ Ejidos são terras resultantes do processo de Reforma Agrária ocorrido no México após a revolução de 1910, com ênfase ao governo de Lázaro Cárdenas (1934-10). A respeito vide Warman (2002). 
|94|

Elites empresariais e a configuração de espaços...

1998; Antochiw, 1998; Antochiw y César, 1991; Macías Zapata, 2002, 2004) informavam a passagem da ilha por diversos ciclos econômicos, alguns de bastante importância para o então território de Quintana-Roo, tendo Cozumel controlado durante o período áureo da produção do chicle ${ }^{8}$ e da copra ${ }^{9}$, bem como da exploração florestal, todo o movimento de exportações destes produtos vindos do continente.

Uma questão que se tornou central à compreensão da configuração socioespacial e da dinâmica atual do turismo na ilha foi entender o processo e as condições sociais, políticas e econômicas que fizeram de Cozumel o segundo destino turístico de cruzeiros no mundo ${ }^{10} \mathrm{e}$, ao mesmo tempo, compreender como formou-se e se consolidou essa elite político-econômica na ilha. Os dados que aqui apresento buscam responder a estas questões.

\section{Configuração socioespacial: núcleo urbano e infraestrutura turística}

A Cozumel turística, da qual depende em grande medida a população da ilha, se compõe de uma diversidade de equipamentos turísticos distribuídos ao longo da costa - exceto a zona arqueológica de San Gervasio e o povoado de El Cedral, situado este último a quatro quilómetros para o interior da ilha (veja o circuito na figura II abaixo) assim como uma rede de hotéis e serviços distribuída não apenas na zona costeira, mas no núcleo urbano, que experimentou um crescimento vertiginoso, paralelamente ao crescimento populacional.

\footnotetext{
${ }^{8}$ Tziclit em maya, o chicle é um látex extraído da árvore do Chicozapote, que ficou conhecido como "árvore do chicle", encontrada nas selvas dos estados mexicanos de Campeche e Quintana-Roo, a partir do qual se produz a goma de mascar.

${ }^{9}$ Fibras do coqueiro usadas para fabricação de cordames, selaria e outros.

${ }^{10}$ A respeito vide Santander e Ramos Díaz (2011).
} 
Quando se caminha da costa ocidental à costa oriental, atravessando o núcleo urbano, nota-se que houve uma expansão das avenidas paralelas à Rafael Melgar, esta situada a beira-mar). Até os anos 1980 havia cerca de sete avenidas paralelas à beiramar e em 2011 este número havia quadruplicado (28 avenidas). Na direção Norte-Sul ocorreu o mesmo. Mas uma vez que a parte Norte é limitada pelo Aeroporto, a área urbana cresceu mais em direção ao Sul.

Figura II - Mapa da ilha de Cozumel (2012): pier, zonas de arrecifes y diving; zonas arqueológicas e praias

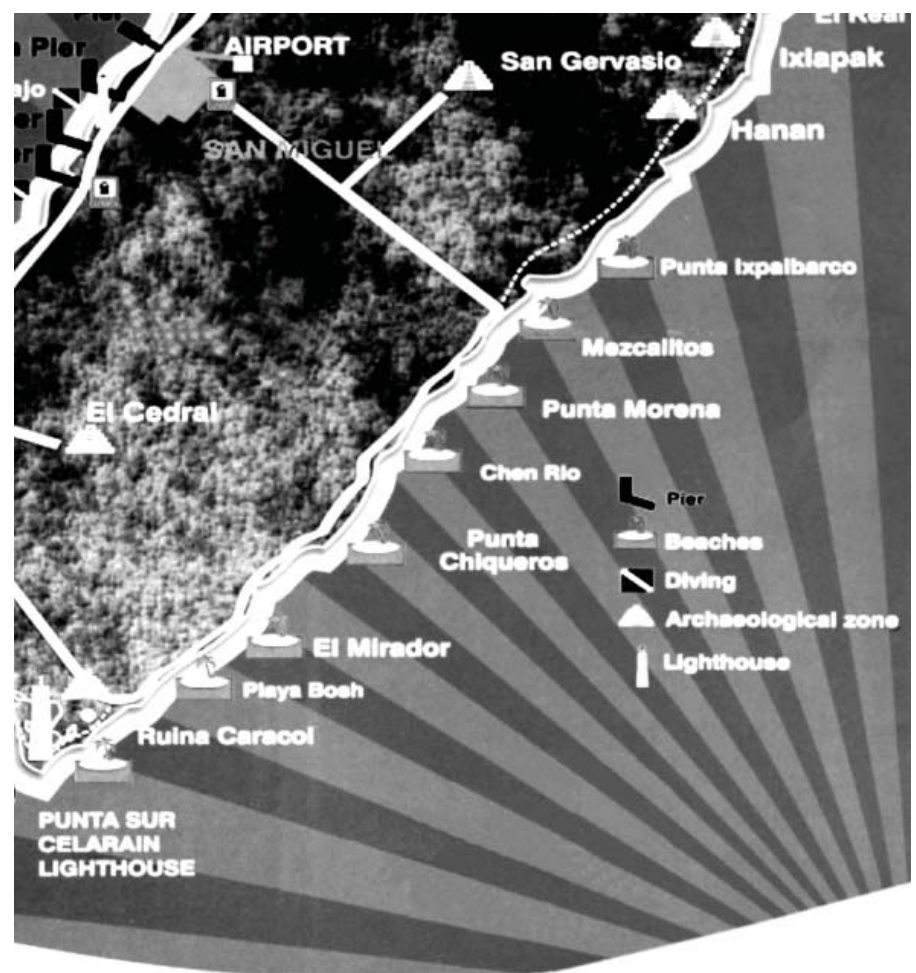

Fonte: Elaborado a partir de plano turístico de livre distribuição. 
|96|

Elites empresariais e a configuração de espaços...

Toda a área que vai dos arrecifes de Palancar, ao Sul, até Playa San Juan, ao Norte, na costa ocidental, é ocupado majoritariamente por hotéis All inclusive ${ }^{11}$. $\mathrm{O}$ acesso às praias ou arrecifes é, portanto, controlado pelos donos de hotéis e clubes de praia. Estes condicionam o uso da praia e as atividades de snorkelling ${ }^{12}$ e mergulho ao consumo de alimentos e bebidas pelos visitantes. Além do mais, os hotéis proíbem a passagem dos não hóspedes. Neste sentido é que Martínez (2007, p. 135), ao construir uma tipologia dos espaços costeiros de uso turístico e recreativo em Cozumel, aponta como um dos resultados de sua tese "la disminución de los sitios costeros abiertos", as praias públicas, "a medida que se avanza desde la ciudad sobre el eje norte-sur de la costa oeste".

Uma simples caminhada de duas quadras, no sentido beira-mar /centro, em direção à costa Leste da ilha, evidencia a segregação espacial entre a ilha dos turistas e a ilha dos moradores. A estrada circunscreve uma superfície de mais da metade da ilha, no sentido Leste-Oeste e em sua parte Sul. Na área central existe ainda uma cidade não turística, habitada pelos que trabalham para o turismo. Há nesta região um movimento intenso de carros e motos em razão da péssima qualidade do transporte público, questão que será retomada no tópico seguinte, no qual serão abordadas as relações de poder.

\footnotetext{
${ }^{11}$ Hotéis cuja diária inclui alimentação, bebidas e todas as atividades de recreação e lazer.

${ }^{12}$ Forma de nado para apreciação dos arrecifes e fauna marinha, com o corpo à superfície e uso de máscara e tubo para respiração.
} 
Figura III - Plano urbano e principais bairros (2006)

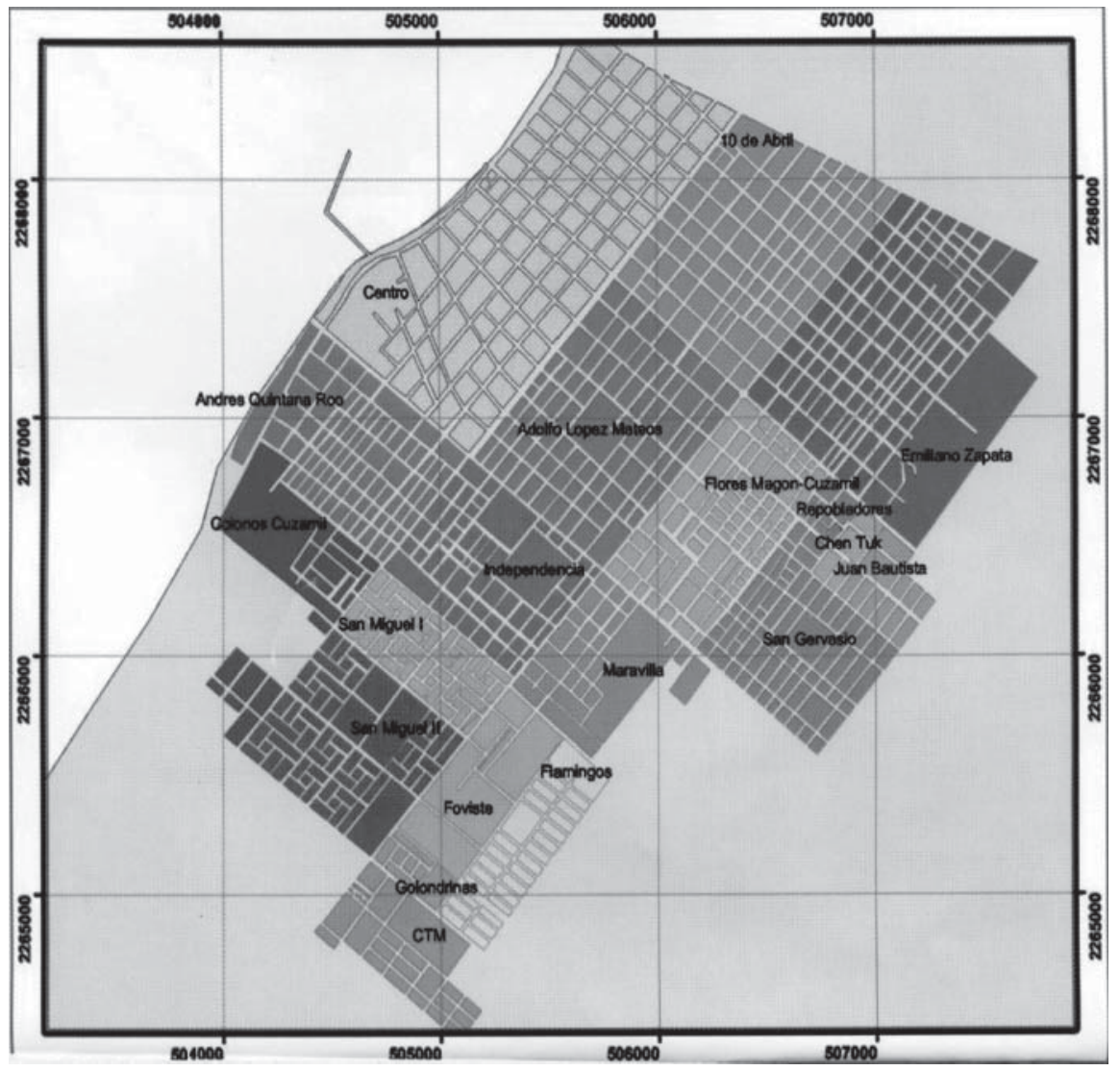

Fonte: FRAUSTO MARTÍNEZ, Oscar (coordinador). Indicadores de desarrollo humano. Cozumel, Quintana=Roo, Reporte 2005. Observatorio Urbano Global de la Riviera Maya. ONU-Hábitat, 2006.

Nesta parte da ilha estão as escolas, as instituições públicas, os bancos, as universidades; também há grande quantidade de lojas de roupas móveis, farmácias, padarias e um dos três únicos postos de gasolina existentes na ilha; também hospitais, centro médico e consultórios médicos e dentários; restaurantes simples, bares, oficinas mecânicas, os edifícios dos sindicatos de taxistas (este o 
|98|

Elites empresariais e a configuração de espaços...

maior e mais imponente), dos guias turísticos, dos trabalhadores em hotéis, bares e restaurantes; de tal modo que existe uma infraestrutura urbana para atender a todas as necessidades dos moradores.

A mancha urbana se compõe de mais de 18 bairros e novas expansões estavam planejadas em 2011. A composição dos bairros expressa diferenças sociais entre os antigos e os novos moradores. As classes mais abastadas se localizam nas regiões próximas ao centro e na área costeira da parte Norte e Sul. Nos bairros 10 de abril e Emiliano Zapata são mais elevados os índices de pobreza. San Gervasio, Juan Bautista, ChenTuk, os mais periféricos, representam novas ampliações e têm índices mais elevados de desemprego (Frausto Martínez, 2006). São ocupados no geral por novos migrantes que chegam do continente em busca de trabalho e da possibilidade de aquisição de uma casa, em razão das seguidas ampliações da mancha urbana. Abrigam não apenas os novos migrantes; eles também recebem antigos moradores de classe média baixa ou baixa que venderam suas casas, onde suas famílias viveram por décadas, na região central, mais valorizada, e compraram outras casas nas zonas mais distantes.

Também nas áreas periféricas existem bairros habitados por pessoas já estabelecidas na ilha; criados por pressão de grupos de poder locais, como os empregados do setor público, taxistas e outros (CTM, Golondrinas, Foviste, Flamingos). Desta forma, a Cozumel não turística é semelhante a um mosaico social, com agrupamentos por setor de atividade, profissão, condição social; além, é claro, do nível das relações com o poder público e com o poder político.

Martínez (2007) identificou 74 espaços costeiros em Cozumel e construiu uma classificação deles segundo seu uso turístico e recreativo e em acordo a setores territoriais: o centro, a parte Norte da ilha, a área urbana aonde estão residências, condomínios, hotéis, clubes de golf; a parte Sul aonde estão os clubes de praia que recebem os turistas de cruzeiros; hotéis tipo resort e dois parques naturais (Chankanaab e Punta Sur) que são importantes pontos turísticos da ilha. Uma região intermediária entre a mancha 
urbana e o início da área de hotéis e clubes de praia, a autora classificou como Centro-Sul.

O setor Este é o trajeto mais extenso e do qual se poder ver o mar em toda a sua extensão; menos povoado, se situa no outro extremo longitudinal da ilha, mas é uma área protegida para desova de tartarugas marinhas. Ali existe apenas um hotel que ninguém soube me explicar como obteve autorização para funcionar. Ao longo desta parte desabitada, sem hotéis e voltada para o mar aberto, perigoso, estão distribuídos alguns espaços turísticos, predominantemente bares/restaurantes com características particulares: "Los rastas" no extremo sul da ilha é um bar que evoca o reggae e a cultura hippie; "Coconuts" e Playa Bonita são bares/restaurantes situados em áreas de encosta, com excelente vista do mar. Há apenas um clube de praia nesta parte da ilha, Punta Morena, frequentado majoritariamente pelos locais, nos finais de semana. Há dois mirantes, Mezcalitos e El mirador, onde descem os turistas que escolhem fazer um passeio pela ilha de carro ou jeep, bugs e outros pequenos veículos, muito coloridos, alguns muito, muito pequenos e arredondados, semelhantes a insetos coloridos com suas antenas na parte dianteira. Nos dias de cruzeiros, os turistas infestam a ilha de pequenos veículos, principalmente na parte Sul y Leste. No entanto, uma vez que a tipologia de Martínez (2007) se restringiu aos espaços costeiros, ficam de fora um grande número de hotéis médios e pequenos localizados no coração do núcleo urbano e atualmente, inclusive, em suas áreas periféricas.

Cozumel conta com cerca de dez agencia de viagem espalhadas pela cidade e 41 dives, sendo que o número real é bem maior se englobarmos os existentes acoplados aos hotéis (Chan Ventura, 2006, p. 43) ${ }^{13}$. Os dados de observação mostraram a existência na zona turística urbana de aproximadamente 33 lojas de mergulho, 23 restaurantes de padrão médio a alto; 67 pequenas lojas de artesanato e produtos diversos; 16 grandes lojas

${ }^{13}$ Ver também http://www.scuba-diving-cozumel.com/cozumel_dive_shops. html. Consulta em: 05/03/2012. 
| $100 \mid$

Elites empresariais e a configuração de espaços...

de artesanato; 16 joalherias grandes de padrão internacional e 42 joalherias médias e pequenas; duas grandes lojas duty-free que vendem principalmente perfumes, cremes, e relógios. Há ainda aproximadamente 65 lojas de roupas e 14 pontos de vendas de passeios turísticos situados na saída do atracadouro central de barcos de passageiros vindos do continente, praça central e outros pontos da avenida Rafael Melgar, em sua parte central. Outras lojas são as mercearias, as de aluguel de carros (10), as barracas situadas à margem da praia, com bares, restaurantes; além de três danceterias. Os clubes de praia situados na zona Sul, na parte ocidental da ilha, são 11 e recebem comumente turistas de cruzeiros.

Toda esta infraestrutura está preparada para atender a demanda de até oito cruzeiros aportados na ilha ao mesmo tempo, quando até vinte mil turistas, além da tripulação, podem descer à terra em um só dia. Como ocorreu em fevereiro de 2012, quando a ilha recebeu, na última semana do mês um total de 24 cruzeiros, setenta mil passageiros, com a expectativa de uma entrada de aproximadamente quatro milhões de dólares ${ }^{14}$. Para março esperava-se um aumento do número de embarcações, para 27, com 80 mil passageiros a bordo e expectativa de ingresso de seis milhões de dólares ${ }^{15}$.

\section{Os grupos de poder e o desenvolvimento da ilha como destino turístico}

Já nos primeiros dias de estada em Cozumel foi possível notar alguns detalhes quanto às relações sociais e aos grupos de poder na ilha. Os taxistas, por seu número elevado e o conteúdo das informações que ofereciam quando se perguntava algo sobre

\footnotetext{
${ }^{14}$ Ver: http://www.quequi.com.mx/2104_cozumel/1486948-desciende-arribode-cruceros.html. Consulta em: 10/03/2012.

${ }^{15}$ Ver: http://www.vocero.qroo.gob.mx. Consulta em 05/03/2012. "Recibirá Cozumel alrededor de 130 cruceros durante marzo informa la APIQROO”.
} 
a ilha, já mostravam sua importância na configuração das relações de poder na ilha.

Nas conversas com comerciantes, prestadores de serviços e moradores, sobre a situação do turismo em Cozumel, ficou evidente a importância de alguns grupos político-econômicos formado por famílias da ilha. A explicação para a dificuldade atual com a sustentabilidade de seus negócios ou atividades era sempre marcada por uma frase: "lo que pasa es que hay algunas familias que dominan todo...todo está en sus manos...", mas não ficava claro quem eram estas famílias nem porque seriam responsáveis pelas dificuldades dos pequenos empresários e prestadores de serviços.

A única pessoa citada nominalmente (embora muitas vezes a referência não fosse explícita e simplesmente se dizia "¿tu sabes a quien me refiero, no sabes?" é Dom Nassim Joaquín,, um dos filhos de Dom Pedro Joaquín Musa, um imigrante libanês que chegou ao continente em 1916 e com o tempo se tornou um dos mais importantes negociantes da ilha. D. Nassim é o único filho vivo deste primeiro Joaquín, e ainda hoje, aos 94 anos, ele ativamente administra seus negócios e, sobretudo, influi na vida política da ilha e de Quintana Roo, estado responsável por 35\% das entradas de divisas no país em razão do turismo. Dizem os moradores que "nada pasa en Cozumel sin el permiso de D. Nassim", embora para muitos isto não seja nada mais que um mito, uma construção do imaginário social de forte conteúdo simbólico. Há um dito popular que ouvi diversas vezes e que conta mais ou menos o seguinte: “Dizem que se encontraram dois indivíduos, um de Cozumel e outro de fora. $\mathrm{O}$ estrangeiro perguntou ao nativo da ilha: É verdade que D. Nassim é de Cozumel? Ao que ele respondeu: "Não, Cozumel sim é de D. Nassim".

De forma burlesca ou explícita, às vezes balbuciando ou olhando para os lados, a conferir se alguém nos ouvia, os moradores sugeriam que existe um controle por parte desta pessoa e sua família sobre tudo o que ocorre na ilha, razão porque muitos se recusavam a falar, por medo de serem punidas. Ouvi relatos do caso de um jornalista que ao tecer críticas a esses grupos de poder, 
|102 |

Elites empresariais e a configuração de espaços...

em um jornal local, foi ameaçado e teve que abandonar a ilha. Diz-se o mesmo de um parente próximo, gentilmente afastado da ilha e hoje residente na Cidade do México. Ainda que sejam apenas relatos, de difícil comprovação, o fato é que os jornais locais são todos acríticos, apenas relatam os acontecimentos concernentes à ilha, diferentemente dos jornais publicados no continente que tecem críticas abertas a esses grupos.

De posse dessas primeiras informações e já consciente de que necessitaria muito cuidado com o desenvolvimento de estratégias para obter informações, só pude ter uma dimensão mais exata da dinâmica das relações na ilha quanto tentei estabelecer os primeiros contatos para o início da pesquisa.

Primeiramente houve uma pronta disponibilidade de auxílio por parte de pesquisadores e da coordenação da Universidade de Quintana Roo - UQROO, o que se revelou também como uma sutil forma de controle sobre minhas atividades, dado que eu passei a depender da intermediação desta universidade para obter entrevistas com os que eles denominavam "personalidades de Cozumel". A princípio isto me causou incômodo, mas os acontecimentos posteriores me fizeram compreender as dificuldades existentes a quem tenta caminhar só na condução da pesquisa. Na tentativa de contato e busca de dados com o presidente da Comisión Ejidal ${ }^{16}$, uma tentativa de caminhar por meus próprios pés, foi bastante desastrosa. Eu buscava compreender o processo pelo qual o ejido de Cozumel perdeu $80 \%$ das terras que haviam sido concedidas em 1945, e nunca me havia ocorrido, em toda minha experiência como pesquisadora, uma situação como a que tive que enfrentar em Cozumel. O então presidente da Comisión Ejidal, um médico local, o que me causou certa estranheza, disseme:

\footnotetext{
${ }^{16}$ É próprio do sistema de ejidos a eleição de uma comissão que age em nome dos ejidatários e a representa perante as instâncias públicas e legais. Esta comissão é também responsável pela realização de assembleias periódicas e decisões quanto ao futuro do ejido.
} 


\begin{abstract}
Aquí es un ejido muy particular, nadie trabaja la tierra,...somos todos profesionistas porque nuestros abuelos y nuestros padres nos enviaran a estudiar. Yo salí de Cozumel a los quince años y volví diez años después; hay aquí ejidatarios médicos como yo, también abogados, comerciantes...
\end{abstract}

Sobre sua negativa em me fornecer os dados de arquivo solicitados me disse apenas ser esta uma questão ética, uma vez que ele representava um coletivo de 124 pessoas. A primeira concordância em me conceder nomes de ejidatarios que me pudessem conceder entrevistas tornou-se uma negativa quando de meu regresso a seu consultório na data e horário aprazados. Depois de horas de espera eu pude falar com ele rapidamente, quando saia para o almoço. Visivelmente irritado ele me perguntou porquê eu estava ali e me afirmou que não havíamos marcado nenhum encontro nem que havia me prometido fornecer lista de ejidatários, isto porque, segundo ele, eu mesma havia decidido colocar fim à pesquisa ao ver que não teria acesso aos dados solicitados. Estava claro que não seria fácil obter dados e entrevistas atuando de forma isolada e que, a princípio, a UQROO seria fundamental para que eu pudesse construir uma rede de relações em campo. O mais importante, entretanto, foi constatar o elevado grau de controle e hierarquização nas relações sociais em Cozumel. Compreendi melhor o medo que transparecia nas conversas com os trabalhadores do ramo turístico, sobretudo quando eu tentava obter deles maiores informações. Com o tempo tive a certeza de que estes grupos de poder, e com certeza D. Nassim, acompanhavam os caminhos de minha pesquisa. Ou melhor, que de alguma forma a minha passagem por certas instâncias, sobretudo nas esferas de poder local - prefeitura e órgãos estaduais - chegava ao seu conhecimento e por sua intervenção procuravam todos controlar e mesmo impedir o meu acesso aos dados.

Os episódios evidenciaram o alto grau de controle exercido pelos detentores de poder na ilha, um controle que abarca todas as dimensões da vida social. Para que se tenha uma ideia, quando regressei ao CIESAS, em Mérida, fui informada pelo diretor 
| 104 |

Elites empresariais e a configuração de espaços...

daquela unidade que de Cozumel haviam telefonado buscando certificar-se de meu vínculo com a instituição. Por outro lado, estes acontecimentos se converteram em importantes indicativos analíticos, inclusive porque outros dados de observação, dados secundários e entrevistas, mostravam que a configuração dos grupos de poder formava um tramado intrincado e de difícil desenlace. Uma entrevista em especial, com uma pessoa que vive há dezessete anos em Cozumel, mas é natural da Cidade do México e atua no ramo de hotelaria, foi de grande contribuição para esclarecer alguns pontos destas redes amplas que conectam quase todos os habitantes da ilha por meio de relações hierárquicas e/ou de dependência. A interpretação da entrevistada era que:

La isla esta conformada por grupos; grupos de poder por tanto. Y luego viene el grueso de la población, que no son grupos de poder salvo que la población en general. Estos grupos han mantenido en la isla, desde que yo la conozco, en un equilibrio é... sano por un lado, porque no ha habido un crecimiento desmedido ni desbordado, pero que hoy por hoy en permanecer así nos está costando ser poco competitivos frente al que esta pasando en el resto del estado y del país.

Das observações acima, é importante reter esta presumida conexão entre a configuração e atuação dos grupos de poder na ilha e a perda de competitividade econômica de Cozumel no mercado turístico. Mas como se daria esta relação de causa e efeito, sendo confirmado o raciocínio da entrevistada?

A partir deste depoimento eu compreendi parte dos dados coletados até então. O primeiro ponto, que em Cozumel a maioria das pessoas, para não dizer a totalidade, de alguma forma mantém relações de interdependência, estava cada vez mais claro. Mas eu não compreendia como, mesmo com o crescimento do município, estas redes de interdependência persistiam e incluíam os novos moradores no mesmo padrão de relações. Como um sistema que funciona com três ou cinco mil pessoas, que era o número de 
habitantes de Cozumel até meados do século XX, persiste com 60, 70, 80 mil moradores?

Os principais grupos de poder em Cozumel são: i) os grupos políticos, que se cruzam com os grupos econômicos, sendo que Joaquines y Gonzales são os principais grupos familiares competidores na arena política - poder público municipal, Cozumel e outros municípios do estado de Quintana-Roo, inclusive Cancún, poder público na esfera estadual, câmara de deputados e senado federal. Parte dos Gonzalez tem laços de parentesco com os Joaquines e parte dos Gonzales tem alianças com os Borge, Martín, Ângulo e outras famílias com expressividade na cena política; ii) os sindicatos de taxistas, estivadores, músicos, empregados em hotelaria, bares e restaurantes e de guias de turismo; iii) associações ambientais, de estrangeiros residentes em Cozumel, Ongs, etc.; iv) grupos empresariais externos: hotelaria (grupos empresariais internacionais), operadoras turísticas e empresas de transporte marinho que controlam a conexão da ilha com o continente (passageiros, veículos e abastecimento da ilha). Embora de certa forma eles estejam interconectados, seja por alianças, dependência, ou divisão de atividades, me deterei neste artigo nos grupos familiares de moradores da ilha que detém poder econômico e político sobre ela e seus moradores.

\section{Grupos familiares e poder político-econômico na ilha de Cozumel}

É muito forte o respeito dos habitantes da ilha para com os empresários pertencentes a esses grupos familiares, em especial a D. Nassim Joaquín, uma figura já quase mítica em Cozumel. Um dado importante é que uma vez que estas famílias poderosas garantem o controle político sobre a ilha e muitas vezes sobre o estado de Quintana-Roo, ficam em suas mãos as concessões para as atividades de taxistas, restaurantes, vendedores e outros; assim como a concessão de uma parcela de terras do fundo municipal 
|106 |

Elites empresariais e a configuração de espaços...

por ocasião da inauguração de novos assentamentos urbanos. E é assim que os novos habitantes da ilha se veem enredados na mesma trama. Quando chegam à ilha necessitam de moradia e emprego; e para tudo isto dependem deste mesmo pequeno grupo de empresários.

Desta forma é que me deparei muitas vezes com depoimentos aparentemente contraditórios. Um taxista entrevistado, hoje com 52 anos, cuja família vive na ilha desde os princípios do chamado repovoamento conta (ou interpreta) a forma como estes grupos poderosos obtiveram sua fortuna:

Colombia (una vasta región al sur de la isla), era el lugar donde los barcos llegaban...podríamos decir, era como hoy en día se desembarca la droga sí? Contrabando sí. Porque el contrabando en aquel tiempo era whisky, los perfumes franceses, queso de bola y todo era puro contrabando.... Todo lo que aquella época era contrabando depois se tornou duty-free",

diz o entrevistado em tom de picardia. Com estas referências, ainda que não sejam nomeadas as pessoas, não é difícil concluir a quem ele se refere porque se sabe quem são os donos das lojas de duty-free na ilha. Entretanto, ao final da entrevista o taxista conclui que são pessoas vitais para a ilha. Ao mais poderoso, D. Nassim, ele atribui poder quase total no âmbito político:

D. Nassim Joaquin Ibarra, él era quien decía: tú vas a ser gobernador de Quintana-Roo y tú eras. Tú vas a ser presidente municipal de Cozumel le decía D. Nassim y era. Por ahora, D. Nassim tiene una hija que es senadora por la República...mexicana. El que está como presidente municipal ahora, es un nieto de D. Aurelio Joaquín. D. Nassim Joaquin Ibarra, él era quien decía: Tú vas a ser gobernador de QuintanaRoo y tú eras. Tú vas a ser presidente municipal de Cozumel, le decía D. Nassim... y era. 
E poder igual ele confere ao mesmo empresário, na esfera econômica:

[...] Si, porque es verdad. D. Nassim no sabe ni lo que tiene. Digo así porque las únicas, las gasolineras que existen acá, que son: la que está en la 30, la que está en Puerta Maya, la que está en la 75, la que está en Guacila... son cuatro, son de él. No dejan entrar, no hay otro concesionario que les ceda Pemex. ¿Por qué? Porque D. Nassim aquí es poderoso. Porque hay otras personas poderosas, hay mucha gente de Cancún, inclusive de otras partes de México, no sé que de otras partes, pero han querido meter su negocio y $\mathrm{D}$. Nassim las frena.

O poderio político da família Joaquin é inquestionável. Um de seus filhos foi governador do estado de Quintana-Roo; sua filha foi senadora, casada com um político que tentou fazer carreira em Cancún. Também é verdade que um filho seu com outra mulher que não sua esposa atua em Playa del Carmen, onde foi prefeito, e que seu sobrinho-neto é hoje o prefeito de Cozumel.

O entrevistado considera os Joaquines e os Gonzalez como do mesmo grupo familiar, já que ocorreram casamentos entre eles, e embora todas as crítica por ele feitas, considera a todos pessoas muito respeitadas, "uma dinastia", como afirma, mas fundamentais para a sobrevivência da ilha, porque "si no fuera por D. Nassim mucha gente se quedaria desempleada. Mi hermana trabaja con D. Nassim, mi hermano trabaja con D. Nassim", o que revela a extensão das redes de dependência. Na realidade, por toda a cidade, em conversas informais, diz-se que é elevado o número de pessoas que este poderoso senhor emprega, cerca de 600 pessoas, dizem, apenas em empregos diretos, mas há uma rede muito mais ampla de empregos indiretos e por favores.

Embora o entrevistado tenha conferido um poder de vida e morte a D. Nassim, provavelmente falava com mais desenvoltura na entrevista porque estava desempregado e demonstrou ter um 
|108 |

Elites empresariais e a configuração de espaços...

conhecimento e habilidade para se deslocar entre as intricadas redes que conformam a política na ilha. Ele disse:

Yo aquí le puedo decir quien es quien, yo sé también donde ir acá también, yo sé donde caminar, si, donde puede pasar algo, donde no puede pasar algo, si. Los licenciados acá de los ministerios públicos federales, a ellos reciben dinero toda semana de todos los ... (no nombra quien). Ellos mismos les dan casa, les dan moto, les dan teléfono celular, pero para que quiero ir a la cárcel..

O depoimento faz referência à oferta de compensações para agir de forma ilícita, dada sua condição de desempregado, para que aceite trabalhar dentro do sistema, o que ele afirma ter rechaçado.

No campo político, quanto ao suposto poder total atribuído a D. Nassim, vale sublinhar que nada ocorre com uma simples ordem e sim como fruto de uma luta política muito forte com outros grupos, como os Gonzalez, por exemplo. Embora tenham ocorrido casamentos entre os Gonzales e os Joaquines, e a eleição do prefeito municipal em 2011 expresse a subida dos dois grupos ao poder, acontece que a descendência dos Gonzalez é muito ampla uma vez que houve muitas uniões fora do casamento, com filhos que foram reconhecidos e que também atuam na política. Os gráficos de parentesco que apresento abaixo, permitem uma melhor visualização do exposto. 
$|109|$

Lea Carvalho Rodrigues

\section{Gráfico 1: Família Joaquín}

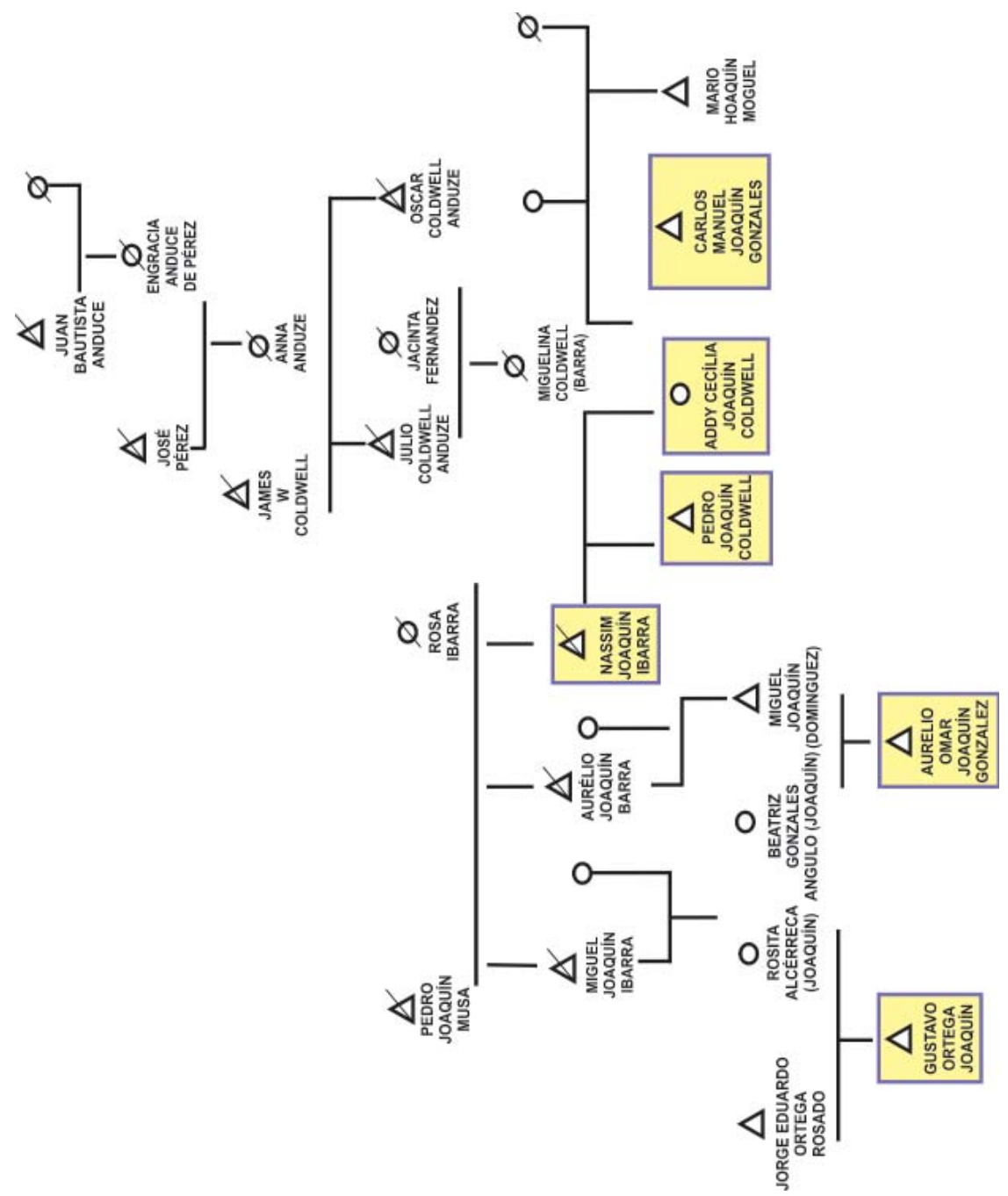

Fonte: Elaboração própria a partir de dados de entrevistas, material bibliográfico e midiático.

Idéias | Campinas (SP) |n. 9 | nova série | $2^{\circ}$ semestre (2014) 
$|110|$

Elites empresariais e a configuração de espaços...

Neste gráfico de parentesco, eu assinalei apenas as pessoas que exercem poder político e econômico na ilha de forma a demonstrar as alianças pelo matrimônio e suas implicações. Por ele observa-se que:

1. D. Pedro Joaquín Musa e Rosa Ibarra tiveram três filhos que se destacaram na vida econômica e política da ilha. Dos três, apenas D. Nassim Joaquín Ibarra está vivo, com 94 anos, e é a figura de maior prestigio da cidade. D. Nassim é o único representante da segunda geração dos Joaquines, desde que estes chegaram à ilha.

2. D. Miguel, irmão de D. Nassim, teve apenas uma filha que se casou com um membro da família Ortega e foi viver em Mérida. Seu neto, Gustavo Ortega de Joaquin, posteriormente se dedicou a política e foi prefeito de Cozumel no período 2005-2008.

3. D. Aurélio, o terceiro irmão de $\mathrm{D}$. $\mathrm{N}$ assim, teve apenas um filho, Miguel Joaquín Domínguez, e este se casou com Beatriz Gonzalez Angulo, duas famílias importantes na ilha, que são competidoras dos Joaquines no campo político-econômico, sendo os Angulo descendentes das chamadas famílias originárias ${ }^{17}$.

4. D. Nassim se casou com a filha do principal competidor dos negócios de seu pai: a filha de Oscar Coldwell, D. Miguelina Coldwell (Ibarra). Embora os relatos digam que não houve aceitação deste matrimônio por parte de ambas as famílias, o certo é que esta união agregou duas importantes fortunas, ainda mais que a descendência dos Coldwell também foi restrita. D. Nassim teve dois filhos de seu casamento com D. Miguelina: Pedro Joaquin Coldwell, que foi governador do estado de QuintanaRoo, além de senador da república, diretor geral de

\footnotetext{
${ }^{17}$ Famílias originais são as que chegaram à ilha no ano de 1848, fugindo à guerra entre mayas e espanhóis, também conhecida como guerra de resistência maya (Marín, 2008).
} 
FONATUR e embaixador do México em Cuba; e Addy Cecília Joaquín Coldwell, foi senadora pelo Partido Acción Nacional (PAN) no período 2003-2006, quando renunciou ao Partido Revolucionário Institucional (PRI), que domina a ilha e o estado, segundo ela por ver frustradas suas pretensões de concorrer ao governo de Quintana-Roo pelo PRI. Embora a imprensa tenha criticado o ocorrido e insinuado uma cisão familiar, outra leitura possível é que se tratou de uma boa estratégia de garantir presença nos dois partidos. Vale notar que Addy foi a coordenadora da campanha no estado de Quintana-Roo, do presidente da república, Felipe Calderón, para o período 2007-2011. Ou seja, sua mudança de partido parece ter sido muito mais providencial e vantajosa para a família Joaquin em suas relações com o novo governo.

5. Outro filho de D. Nassim, fruto de uma relação extraconjugal, Carlos Manuel Joaquín Gonzalez, iniciou sua carreira política sob os auspícios de seu pai, mas não na ilha de Cozumel e sim no município de Solidaridad, no continente. Iniciou a carreira política como deputado federal, em seguida foi nomeado Tesoureiro Municipal do município de Solidaridad (2002-2005), Secretario Estatal de Turismo do estado de Quintana-Roo (20052006) e de imediato concorreu e venceu as eleições para prefeito de Solidaridad (2005-2008). Addy também foi Presidenta do Desarrollo Integral de la Familia (DIF), na gestão de seu esposo como prefeito de Benito Juarez (onde se situa Cancún), o que indica a intenção da família Joaquin de ampliar o poder político para os principais municípios do estado de Quintana-Roo. Aurelio Omar Joaquin Gonzalez, sobrinho neto de D.Nassim, neto de seu irmão Aurélio Joaquin Ibarra, é o jovem prefeito de Cozumel, eleito para o período 20112013.

6. Gustavo Ortega Joaquin, neto de D. Miguel Joaquin Ibarra, também já falecido, e sobrinho-neto de D. Nassim, 
$\mid 112$ |

Elites empresariais e a configuração de espaços...

foi prefeito de Cozumel no período 2005-2008, pelo PAN. Depois de ocupar este cargo foi Secretário de Turismo de Quintana-Roo no governo de Mario Villanueva Madrid e em seguida delegado de FONATUR, o importante órgão de decisões, planejamento e gestão, também responsável pela venda de terras ejidales expropriadas nas áreas turísticas, como ocorreu anos antes em Cozumel.

Todas estas informações são relevantes uma vez que mostram o entrelaçamento do econômico com o político. Todos os empresários citados são, direta ou indiretamente, do ramo turístico: Gustavo Ortega é gerente de hotéis, diretor geral de clubes de praia, hotéis e ranchos; Pedro Joaquin Coldwell é herdeiro dos negócios de seu pai, assim como Addy Joaquín que também é proprietária de agências de turismo e consultoria; Carlos Manuel Joaquín Gonzalez, atuou como empresário antes de se dedicar com mais exclusividade à política. Além do mais, por detrás de todos eles estão os interesses econômicos de D. Nassim, considerado o patriarca do clã pela imprensa e pelas pessoas comuns que em baixa voz o chamam "el tatich", a denominação maya para os seus poderosos chefes, na época pré-hispânica e no período da sublevação maya no continente, no período de 1848-1902.

Exponho a seguir o gráfico das relações de parentesco entre uma descendência dos Gonzalez e sua imbricação com a política atual, na figura do governador do estado de Quintana-Roo, Roberto Borge Angulo: 
Gráfico 2 - Família do ex-governador Felix Arturo Gonzalez Canto

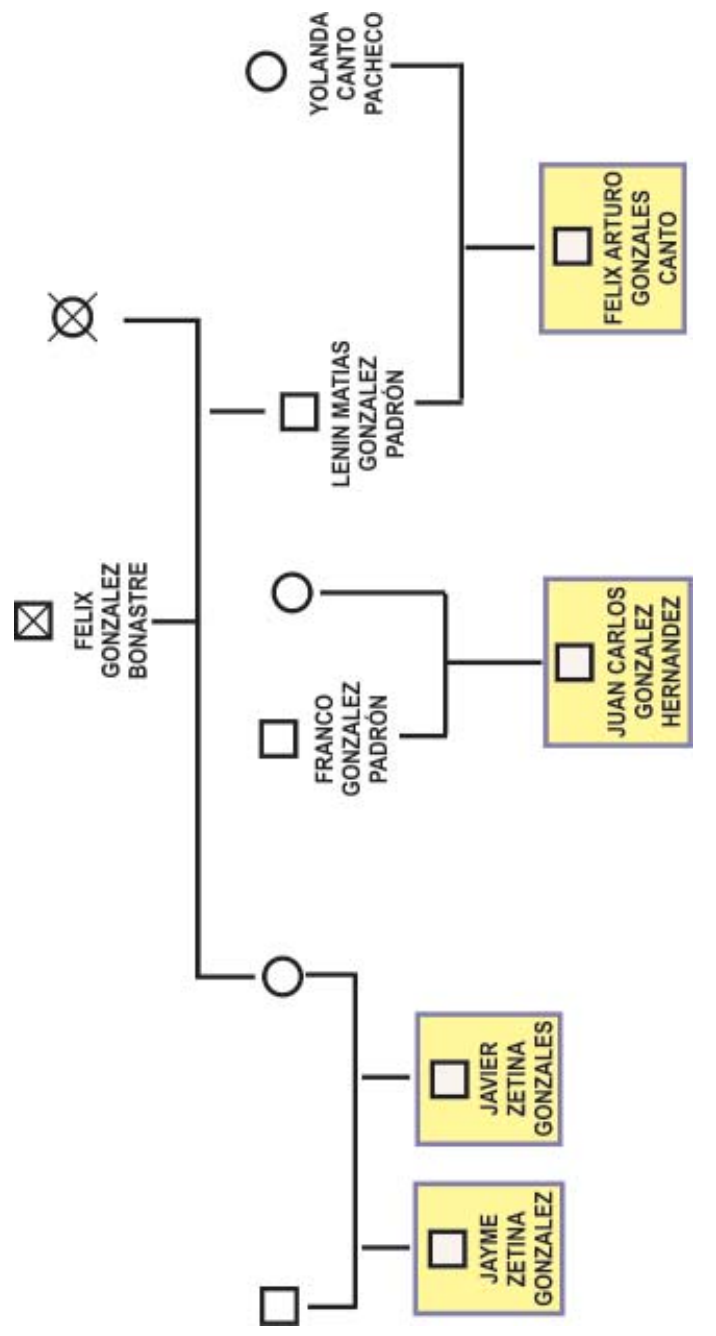

Fonte: Elaboração própria a partir de dados de entrevistas, material bibliográfico e midiático. Os indivíduos assinalados são os que exercem poder político e econômico na ilha e/ou no estado de Quintana-Roo, México. 
|114|

Elites empresariais e a configuração de espaços...

Felix Arturo Gonzalez Canto, neto de Felix Gonzalez Bonastre, o patriarca dos Gonzalez na ilha, foi prefeito de Cozumel (1999-2002) pelo PRI, deputado federal por Quintana-Roo (20032005), governador do estado de Quintana-Roo (2005-2011) e candidato do PRI ao senado por Quintana-Roo no pleito de 2012. O atual governador, Roberto Borge Angulo, é seu afilhado político e sobrinho de Miguel Borge Martín, outro natural de cozumel que ocupou o governo do estado.

Gráfico 3 - Ascendentes do atual governador Roberto Borge Angulo

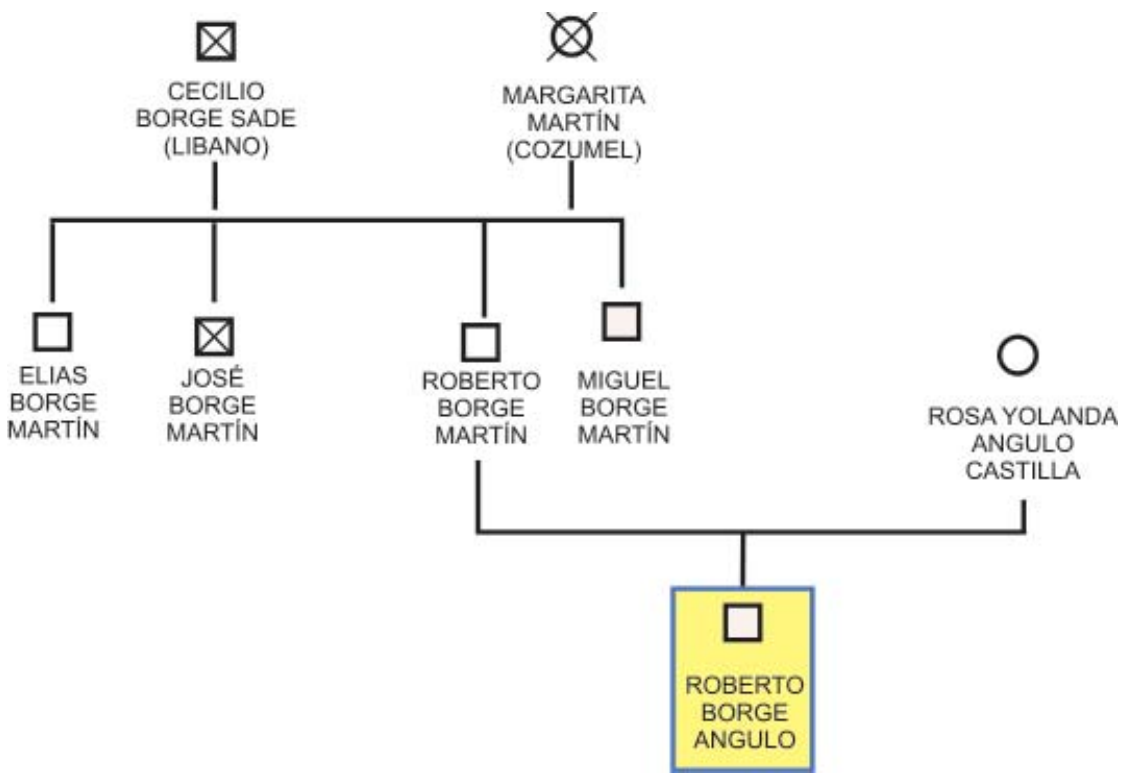

Fonte: Elaboração própria a partir de dados de entrevistas, material bibliográfico e midiático. 
Segundo o jornal Diario de Coauhila de 27/06/2010 ${ }^{18}$ :

Cuando González Canto era diputado federal, Borge Angulo fue su secretario privado. Y cuando llegó a la gubernatura, lo incorporó a su administración, primero como tesorero de la Secretaría de Hacienda estatal y luego como oficial mayor del gobierno quintanarroense. Borge Angulo fue dirigente estatal del PRI y diputado federal, y a principios de año su tío lo impuso como candidato a la gubernatura.

Informa o jornal que o que une os Gonzalez Canto aos Borge Angulo são os interesses econômicos: projetos milionários que só podem se realizar sob o controle do poder político. Segundo o jornal, dentre os envolvidos nestes projetos estão os irmãos Lenin Matias Gonzalez Padrón, pai do ex governador; Franco González Padrón, pai do ex-prefeito de Cozumel, Juan Carlos González Hernández, e Roberto Borge Martín, pai do atual governador (ver gráfico 3).

Somado a tudo isto, D. Felix Gonzalez Canto foi objeto de denúncias de corrupção logo após deixar seu cargo e esteve envolvido com o escândalo do financiamento com recursos públicos dos gastos com o casamento de Roberto Borge. A reportagem de Ernesto Villanueva, de 11/11/2011, intitulada "Quintana Roo: Transparencia e impunidad"19, denuncia que "El ahora exgobernador Félix González Canto ha sido uno de los principales beneficiarios del ejercicio del poder público, donde no dejó ir una sola oportunidad para hacer negocios".

Fica clara, ainda, a ascendência libanesa do atual governador de Quintana-Roo e o costume, em Cozumel, do casamento não endogâmico dos imigrantes libaneses, diferentemente da cidade de Mérida, capital do estado de Yucatán, no continente, vizinha ao estado de Quintana-Roo, onde uma colônia libanesa mais ampla se

18 Veja http://www.eldiariodecoahuila.com.mx/notas/2010/6/27/lomejordelaapro-184841.asp. Consulta en: 30/11/2011.

${ }^{19} \mathrm{http}: / /$ www.proceso.com.mx/?p=287854. 
| 116 |

Elites empresariais e a configuração de espaços...

constituiu e progrediu economicamente por meio de matrimônios endogâmicos (Ramírez, 1994). Ao contrário, em Cozumel a prática foi a aliança com os grupos locais, detentores de terras e negócios bem sucedidos.

\section{Considerações Finais}

Os dados etnográficos mostram que Cozumel é dominada por fortes grupos de poder, representados por poucas famílias que detém o poder econômico na ilha: os Joaquines, a mais importante família local, seguidos dos Gonzales, os Borge, os Angulo e os Anduce. Na verdade, há uma rede de interdependências que envolve a todos que vivem na ilha e isto se relaciona à conjunção do domínio do poder econômico e político por parte dessas famílias, assim como por questões estruturais da política mexicana, como o corporativismo, o caciquismo, as relações clientelistas e a corrupção $0^{20}$.

Foi esta estrutura que permitiu aos Joaquines e aos Gonzales se beneficiarem na compra das terras expropriadas pelo governo em 1974, em especial as situadas na área costeira, as mais valorizadas para o turismo.

Essas famílias dominam ainda as atividades turísticas, deixando pouco espaço para os investidores externos, à exceção de alguns grupos econômicos, também familiares, que gozam de um poder histórico na Península de Yucatán e que têm igual acesso aos centros de poder no México, como os Molina, que é outro caso interessante para estudo da genealogia de parentesco e da trajetória política e econômica de seus membros.

O controle sobre as saídas e entradas de passageiros e mercadorias na ilha, assim como o controle sobre as atividades lúdicas ofertadas aos turistas de cruzeiros está majoritariamente em mão dessas famílias da ilha, como de empresários mexicanos instalados na Península, o que impede alterações na estrutura de

\footnotetext{
${ }^{20}$ A respeito ver Lomnitz (2000).
} 
poder, o que se reflete sobre a atividade econômica e o enfretamento às crises econômicas, desastres naturais (furacões) e ameaças à manutenção da ecologia da ilha e de seus atrativos naturais.

Com base no exposto, eu gostaria de trazer uma breve reflexão sobre as contribuições que a antropologia vem trazendo aos estudos sobre turismo, que se deslocam dos interesses que primeiro moveram os pesquisadores - pensar a relação entre turistas e moradores ou a experiência do turista -, como os vários artigos na coletânea organizada por Smith (1977), ou a visão do turismo como uma nova forma de imperialismo (Nash, 1977), ou ainda como mercantilização da cultura (Greenwood, 1977). A proposta de López y Marin (2011) eu considero como um avanço, pois reivindica uma abordagem mais aprofundada sobre a atuação do Estado no processo de criação de espaços turísticos e na formulação de políticas públicas articuladas, bem como na dimensão cultural e nos aspectos estruturais que conformam as relações de poder que, como vimos no caso aqui apresentado, permeiam toda a vida na ilha e direcionam as atividades turísticas com efeitos consideráveis sobre populações e natureza.

\section{Bibliografia}

ANTOCHIW, M. Cozumel, padrones y poblamiento. Cozumel, Mx: Fundación de Parques y Museos de Cozumel. 1998.

ANTOCHIW, M. y CÉSAR DACHARY, A. Historia de Cozumel. México: Consejo Nacional para la Cultura y las Artes. 1991.

ARROYO ARCOS, L. y GUTIÉRREZ GARCÍA, E. El empleo em el sector hotelero de Cozumel y su impacto en la comunidad. Teoria y Praxis, 3, p. 65-76.2007.

BRINGAS RÁBAGO, Nora L. Desarrollo turístico y dinámica de evolución de usos de suelo en el Corredor Costero TijuanaRosarito-Ensenada (COCOTREN). 1999. 
CÉSAR DACHARY, Alfredo y ARNAIZ B., Stella M.Cozumel. Los años de espera. Cozumel, Mx: Fundación de Parques y Museos de Cozumel, 159 p. 1998.

CHAN VENTURA, Gimer Omar. Historia del turismo de cruceros en Cozumel. Trabajo monográfico, UQROO, Cozumel. 2006

GONZÁLEZ HERRERA, M. y PALAFOX MUÑOZ, A. Producción del espacio turístico em ambientes sensibles. Isla de Cozumel, México y Cayo Lãs Brujas, Cuba. Estúdios y perspectivas em turismo (version on-line), v. 16, n. 2, Ciudad Autônoma de Buenos Aires, abr/jun. 2006.

GREENWOOD, D. J. Culture by the Pound: an Anthropological Perspective on Tourism as Cultural Commoditization. In: Valene Smith (ed.). Hosts and Guests: the Anthropology of Tourism. Filadélfia: University of Pennsylvania Press.1989.

HANNERZ, Ulf. Notes of Global Ecumene. In: Anthropology of Globalization, INDA, J. X. e ROSALDO, R. (orgs.). Blacwell Readers in Anthropology. 2001.

LOMNITZ, C. Vícios públicos, virtudes privadas: corrupción en México. Ciudad de México: CIESAS/ Miguel Ángel Porrúa. 2000.

MACÍAS ZAPATA, G. A. La península fracturada. Conformación marítima, social y forestal del Territorio Federal de Quintana Roo. 1884-1902. México, DF: CIESAS/ Miguel Ángel Porrúa. 2002.

El vacío imaginario. Geopolítica de la ocupación territorial en el Caribe oriental mexicano (coordinador). México, DF: Centro de Investigaciones y Estudios Superioresen Antropología Social (CIESAS), 460 p. 2004.

LÓPEZ SANTILLAN, Á. A. y MARÍN GUARDADO, G. Turismo, globalización y mercantilización del espacio y la cultura en la Riviera Maya: un acercamiento a tres escenarios. Relaciones, 123, vol. XXXI. p. 219-259. 2010. 
MARÍN GUARDADO, G. “Territorio de resistencia, integración mercantil y producción del espacio turístico en Quintana Roo: trayectorias y transformaciones del mundo maya"'" en Turismo, identidades y Exclusión, Alicia Castellanos Guerrero y Jesús Antonio Machuca (Coord), Universidad Autónoma Metropolitana I, Casa Juan Pablos, México (p. 97-141). 2008.

. Turismo, globalización y mercantilización del espacio y la cultura en la Riviera Maya: un acercamiento a tres escenarios en Ricardo López Santillán (ed.), Etnia, lengua y territorio. El sureste frente a la globalización, UNAM, México. 2010.

MARTINEZ, C. I. Tipología de los sitios costeros con usos turístico y recreativo en la isla de Cozumel, México. Tesis de Maestría en Geografía, UNAM. 2007.

NASH, D. Tourism as a Form of Imperialism (1989). In: SMITH, V. (ed.) Hosts and Guests. The Anthropology of Tourism. Philadelphia, University of Pennsylvania Press. (second edition). 1989.

PALAFOX MUÑOZ; ZIZUMBO VILLARREAL. Distribución territorial y turismo en cozumel, estado de Quintana-Roo, México, Gestión turística (Valdivia) n. 11, p. 69-88.2009.

RAMÍREZ, L. A. Secretos de familia. Libaneses y élites empresariales en Yucatán. México, DF: Consejo Nacional para la Cultura y las Artes. 1994.

RAMOS DÍAZ, Martín. Cozumel vida porteña, 1920. México, DF: Universidad de Quintana-Roo/ Consejo Nacional de Ciencia y Tecnología / H. Ayuntamiento de Cozumel/ Fundación de Parques y Museos de Cozumel, 130 p. 1999.

RIBEIRO, G. L. e BARROS, F. L. A corrida por paisagens autênticas: turismo, meio ambiente e subjetividade na contemporaneidade. Serie Antropologia 171, Unb. 1994.

RIBEIRO, G. L. A condição da transnacionalidade. Brasília: Série Antropologia, 223. 1997. 
SÁNCHEZ CRISPIN, Á. y PROPIN FREJOMIL, E. Dependências regionales del turismo en la isla de Cozumel, México, Cuadernos de Turismo, 11, pp. 169-180. 2003.

SCHILLER, N. G. Transnationality (chapter 28). In: NUGENT, David and VINCENT, Joan (ed) A companion to the Anthropology of Politics. Oxford: Blackwell Publishing Ltd. 2007.

SANTANDER, L. C. y RAMOS DÍAZ, M. El nacimiento de un destino turístico en el Caribe Mexicano. Cozumel, de isla abandonada a puerto de cruceros, El periplo sustentable, n. 21, julio a diciembre/2011.

SEMANARP - Secretaria de Medio Ambiente, Recursos Naturales y Pesca - Programa de manejo Parque Marino Nacional Arrecifes de Cozumel. México, 1998.

SMITH, V. L. Hosts and Guests. The Anthropology of Tourism. University of Pensilvania Press. 1977.

ORGANIZACIÓN MUNDIAL DE TURISMO (UNTWO). Disponible en:

http://www.unwto.org/facts/eng/pdf/barometer/unwto_ barom07_2_en_excerpt.pdf. Consulta:13/07/2011.

http://aboutourism.wordpress.com/2011/01/18/unwto-worldtourism-barometer-advance-release-international-tourism2010-multi-speed-recovery/.Consulta: 13/07/2011.

URRY, J. The tourist gaze.London: Sage, 2002 (2ª edición). 2002.

VIVAS VALDÉS, V. Forjadores. Personalidades sobresalientes en la conformación de La identidad cozumeleña. Cozumel, Q. Roo, México: TVC Producciones Guadalajara, 2001.

Travesía por la história de cozumel. Breve monografia histórica. Cancún, México: Editorial Veras, 2008.

WARMAN, A. El campo mexicano en el siglo XX. México, D. F.: Fondo de Cultura Económica. 2002. 